\title{
Statistics Based Fire Risk Analysis on Timber Houses in Japan: Time Factor
}

\author{
YUTAKA KOBAYASHI \\ Technology Center \\ Taisei Corporation \\ Nase-cho, Totsuka-ku, Yokohama, Japan
}

\begin{abstract}
The paper is intended to address the relation between fire damage and time factors related to firefighting activities. Using newly proposed models, the paper studies the probability of exceedance, i.e., the probability of fire damage area to exceed certain levels, and compare model parameters over a wide range of time intervals. As a result, some evidence was obtained that the faster a fire is responded to, the smaller the fire damage is, based on fire statistics of Japan.
\end{abstract}

KEYWORDS: risk assessment, statistics, fire damage, response time, intervention time, wooden construction.

\section{INTRODUCTION}

The log-normal distribution has been widely used in characterizing the distribution of extreme fire losses [1-3]. An alternative statistical model was proposed at the Beijing symposium in 2005 [4]. The model is based on a non-liner soil mechanics formulation called Hardin-Drnevich model [5], fitting fairly well with the probability of exceedance (POE) of such severity measures as monetary loss and floor area damaged by fire collected in Japanese fire statistics [6]. A modification of the procedure was proposed in [7], where the overall risk curve of a series of fire incidents was represented by the product of two independent probability of exceedance functions based on the analysis of timber house fires. The model relates the risk profile in the vicinity of the extreme with the dimension of properties at risk.

Starting with the model, the current paper is intended to address relationships between fire damage area and a variety of time factors: a) time interval between ignition and notification to the fire department or beginning of intervention, b) distance to the closest fire station, and c) first-aid firefighting activities by occupants.

Regarding fire service time intervals, Särdqvist et al. [8] analyzed non-residential building fires from 199497 collected in the Real Fire Database compiled by the London Fire Brigade. One reason that residential buildings were excluded was stated that the size of fire compartmentalization limits the size of fires in residential to a larger extent than other buildings. Various time intervals between firefighting operation events were compared directly with the fire area on double-logarithmic scales. No significant correlation was found between the final fire area and the time interval from ignition to intervention, although time intervals afterwards suggested, not surprisingly, that the larger the fire area, the more time needed in fighting.

On the other hand, the current paper found some evidence that the shorter the time for notification or response to a fire, the less fire damage area is observed.

\section{METHOD}

\section{Database}

The fire statistics were obtained from the Disaster Prevention Information Office, Fire and Disaster Management Agency (FDMA) of Japan. The records analyzed were from 1995 to 2004. The factors examined in the paper include:

- Floor area and fire damage area of the building of fire origin,

- Time intervals between firefighting-related events: ignition, notification to fire departments, and application of water or other agent on the fire, 
- Distance to the closest fire station,

- Measures taken in first-aid firefighting by occupants, and

- Whether or not the fire was responded to by the fire department.

Only the records of one- or two-story residential buildings of timber construction were used, where a valid floor area at risk (equal to or more than 1 square meter) is recorded. This is because the records of this type of building are the richest in numbers.

\section{Firefighting Related Time Intervals from Statistics in Japan}

Regarding firefighting, Japanese fire statistics include the time and date of the following events:

- Ignition of fire,

- Notification to the fire department,

- Application of water or any other extinguishing agent onto fire, only if the fire is responded to by the fire department,

- Fire under control, if responded to by the fire department, and

- Fire extinguished.

Table 1 summarizes events related to firefighting operation by the fire department, commonly used names of the time intervals [8-11] between these events, and the availability of data in the statistics of Japan. The paper focuses on the time intervals prior to the start of firefighting:

- Notification time: measured from ignition to beginning of firefighting.

- Response time: extended for the purpose of the study to include not only dispatch, turnout, and travel times but also set up time.

- Intervention time here is defined as the summation of notification and response times.

It should be noted that the fire area in the statistics of Japan is defined at the end of the fire, unlike the London database where the fire area is available at three points of time: discovery, arrival at fire scene, and the end of the incident.

To extinguish a fire, some manual or automatic actions may be taken prior to the activities by fire departments. The presence and the result of such first-aid firefighting events are recorded in the statistics in Japan. Unfortunately, however, the timing of these events is not available.

Table 1. Event times and time intervals.

\begin{tabular}{|c|c|c|c|c|}
\hline $\begin{array}{l}\text { Availability } \\
\text { in Statistics }\end{array}$ & Events & Names of Time Interval & \multicolumn{2}{|c|}{$\begin{array}{c}\text { Time Interval Addressed in the } \\
\text { Paper }\end{array}$} \\
\hline Available & Ignition & & & \multirow{9}{*}{$\begin{array}{l}\text { Intervention } \\
\text { Time }\end{array}$} \\
\hline & & Discovery Time & \multirow{2}{*}{$\begin{array}{l}\text { Notification } \\
\text { Time }\end{array}$} & \\
\hline NO & Discovery & Notification Time & & \\
\hline Available & Call to Fire Department & Dispatch Time / Call Processing & \multirow{6}{*}{ Response Time } & \\
\hline \multirow[t]{2}{*}{ No } & \multirow{2}{*}{ Dispatch } & Time & & \\
\hline & & Turnout Time & & \\
\hline No & Departure & \multirow{2}{*}{ Travel Time / Drive Time } & & \\
\hline No & Arrival on Fire Scene & & & \\
\hline \multirow{2}{*}{$\begin{array}{l}\text { Available if } \\
\text { respodend to }\end{array}$} & \multirow{2}{*}{$\begin{array}{c}\text { Application of Extinguishing } \\
\text { Agent } \\
\end{array}$} & Set-up Time & & \\
\hline & & \multirow{3}{*}{ Firefighting / Intervention Time } & \multirow{3}{*}{\multicolumn{2}{|c|}{ To Be Addressed }} \\
\hline $\begin{array}{l}\text { Available if } \\
\text { respodend to }\end{array}$ & Fire Under Control & & & \\
\hline Available & Fire Extinguished & & & \\
\hline
\end{tabular}




\section{Models Representing Probability of Exceedance}

The paper deals with the probability of exceedance of two types of quantities: area damaged by fire and time intervals. The probability of exceedance of a variable means here the probability per event of a fire related parameter to exceed a certain level. The probability of exceedance is also referred to complementary cumulative distribution function.

The first procedure to model the probability of exceedance is schematized in Fig. 1, where the probabilities of exceedance of fire damage area are compared with the model for all timber houses in 1995-2004. The model is a product of two exceedance probability functions: base function and reduction factor:

$\mathrm{P}[X>=x]=\Phi\left(\left(x-\mu_{B}\right) / \sigma_{B}\right) \times \Phi\left(\left(x-\mu_{R}\right) / \sigma_{R}\right)$

where

$\Phi$ : the standard normal cumulative distribution function

$x$ : base-10 logarithm of severity measure

$\mu_{B}, \sigma_{B}$ : mean and standard deviation corresponding to base function

$\mu_{R,} \sigma_{R}:$ those of reduction factor

As a special case, the probability of the fire area to exceed the minimum value, the unity, will be approximated as follows since near $x=0$ reduction factor will be roughly 1.0 (Fig.1a):

$\mathrm{P}[\mathrm{X}>=\log 10(1)]=\Phi\left(-\mu_{B} / \sigma_{B}\right)$

or

$\Phi^{-1}(\mathrm{P}[\mathrm{X}>=\log 10(1)=0])=-\mu_{B} / \sigma_{B}$

where

$\Phi^{-1}$ : the inverse standard normal cumulative distribution function

Thus, the probability of the fire area to exceed the unity is represented by the reciprocal of the coefficient of variance $(\mathrm{COV})$ of base function.

It was confirmed that the model performs well in describing the overall profiles of fire risk in terms of area damaged by fire from minimum to maximum of a variety of buildings (Fig. 1).

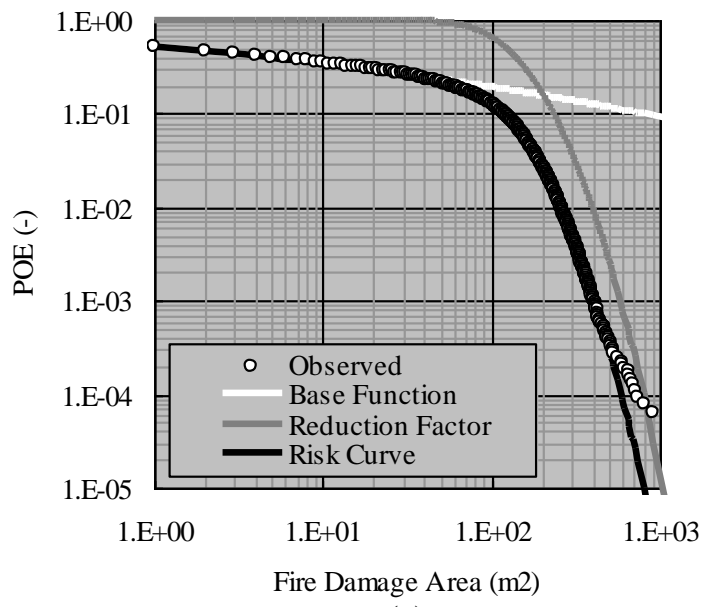

(a)

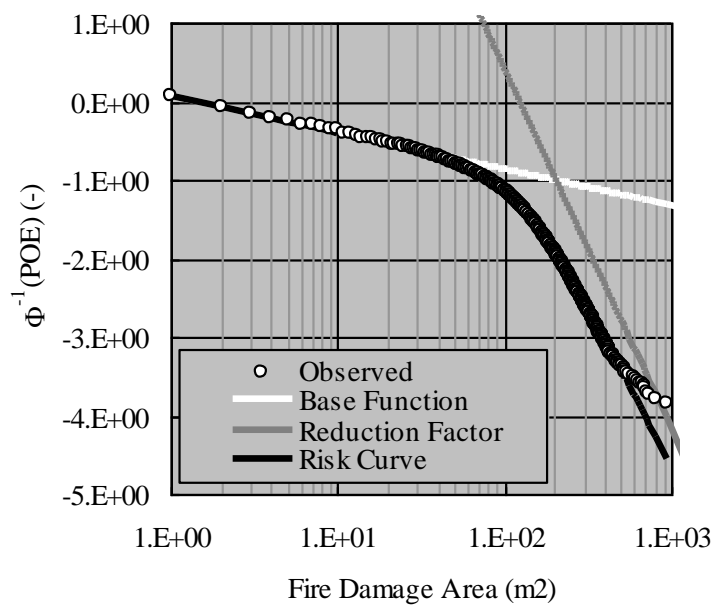

(b)

Fig. 1. Model concept. 


\section{Model for Probability of Exceedance of Time Interval}

Another way of extending the normal distribution model is summation of two exceedance probability functions as below:

$\mathrm{P}[X>=x]=(1-\alpha) \times \Phi\left(\left(x-\mu_{P}\right) / \sigma_{P}\right)+\alpha \times \Phi\left(\left(x-\mu_{S}\right) / \sigma_{S}\right)$

where

$\mu_{P}, \sigma_{P}$ : parameters representing the primary period of time.

$\mu_{S}, \sigma_{S}$ : parameters for the upper tail of the time distribution.

$\alpha$ : ratio of events following the upper tail model

An example is given in Fig. 2, where data of time interval between ignition and extinction are compared with the model.

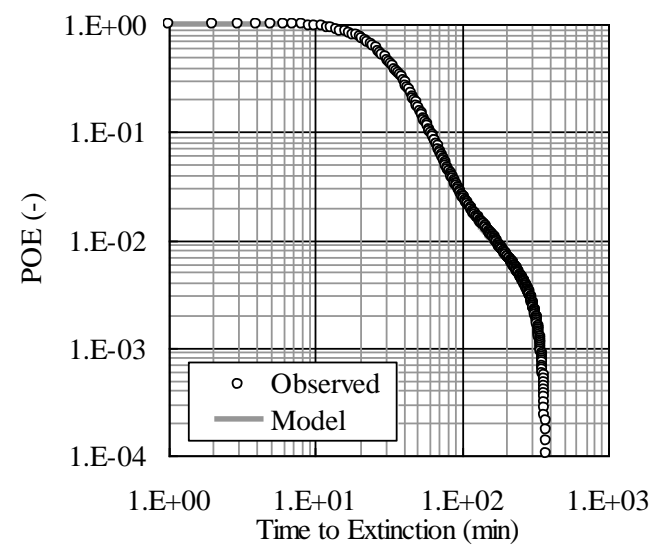

Fig. 2. Model for time intervals.

\section{FLOOR SIZE INFORMATION DERIVED FROM FIRE SIZE CURVE-FITTING}

Japan consists of 47 prefectures. To illustrate the effectiveness of the base function / reduction factor model discussed above, risk curves were generated and analyzed for model parameters on prefecture by prefecture. The results are summarized in Table 2 . 
Table 2. Prefecture-by-prefecture results.

\begin{tabular}{|c|c|c|c|c|c|c|c|c|c|c|c|}
\hline Prefecture & $\mathrm{N}$ & $\overline{\sigma_{\mathrm{B}}}$ & $\mu_{\mathrm{B}}$ & $\overline{\sigma_{R}}$ & $\mu_{R}$ & \begin{tabular}{|l|} 
Prefecture \\
\end{tabular} & $\mathrm{N}$ & $\overline{\sigma_{\mathrm{B}}}$ & $\mu_{\mathrm{B}}$ & $\overline{\sigma_{\mathrm{R}}}$ & $\mu_{R}$ \\
\hline 1 & 1695 & 3.0879 & 1.3702 & 0.2353 & 1.9172 & 24 & 1097 & 1.8596 & 0.0701 & 0.2096 & 2.0928 \\
\hline 2 & 828 & 2.8434 & $\begin{array}{l}1.3777 \\
\end{array}$ & 0.1908 & 2.0774 & 25 & 707 & 1.8741 & -0.01 & 0.252 & 2.102 \\
\hline 3 & 1032 & 2.7322 & 0.808 & 0.2208 & 2.1495 & 26 & 927 & 1.7891 & -0.012 & 0.1974 & 2.1339 \\
\hline 4 & 1647 & 2.1768 & 0.0547 & 0.207 & 2.1476 & 27 & 1647 & 2.2289 & -0.85 & 0.2598 & 1.9583 \\
\hline 5 & 1026 & 2.2111 & 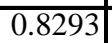 & 0.1828 & 2.2848 & 28 & 2262 & 2.008 & -0.071 & 0.2849 & 2.1024 \\
\hline 6 & 1076 & 2.1647 & 0.3239 & 0.1724 & 2.2348 & 29 & 796 & 2.0459 & 0.2 & 0.251 & 2.0851 \\
\hline 7 & 1799 & 1.8655 & 0.4394 & 0.1523 & 2.2458 & 30 & 638 & 2.0908 & 0.2305 & 0.2371 & 2.0201 \\
\hline 8 & 2482 & 2.5951 & 0.568 & 0.184 & 2.0433 & 31 & 569 & 2.2326 & 0.2315 & 0.172 & 2.1672 \\
\hline 9 & 1500 & 2.256 & 0.4209 & 0.1903 & 2.0737 & 32 & 620 & 2.0454 & 0.0496 & 0.1859 & 2.1618 \\
\hline$\overline{10}$ & 1524 & 2.5713 & 0.2457 & 0.2067 & 2.0548 & 33 & 1592 & 1.8457 & 0.5759 & 0.2035 & 2.1906 \\
\hline 11 & 3365 & 1.8761 & -0.218 & 0.2429 & 1.9942 & 34 & 1426 & 2.1733 & -0.134 & 0.2276 & 2.1447 \\
\hline 12 & 3226 & 2.1913 & -0.051 & 0.1949 & 2.0154 & 35 & 1092 & 1.9923 & 0.2062 & 0.1816 & 2.1284 \\
\hline 13 & 805 & 3.8306 & -2.976 & 0.2966 & 1.7471 & 36 & 543 & 1.5826 & $\begin{array}{l}0.5399 \\
\end{array}$ & 0.1397 & 2.1525 \\
\hline 14 & 2992 & 2.3839 & -0.749 & 0.2991 & 1.816 & 37 & 801 & 1.6633 & 0.8502 & 0.1921 & 2.1597 \\
\hline 15 & 1700 & 2.0506 & 0.1695 & 0.1531 & 2.2545 & 38 & 893 & 2.0954 & 0.3278 & 0.2204 & 2.0576 \\
\hline 16 & 593 & 2.7449 & 0.782 & 0.1597 & 2.2858 & 39 & 610 & 3.0952 & 0.6275 & 0.2214 & 1.9043 \\
\hline 17 & 626 & 2.2546 & -0.181 & 0.1805 & 2.1857 & $\overline{40}$ & 3127 & 2.0794 & -0.046 & 0.1702 & 2.1224 \\
\hline 18 & 450 & 1.6168 & 0.1082 & 0.1647 & 2.3512 & 41 & 708 & 2.2012 & 0.3443 & 0.1808 & 2.2216 \\
\hline 19 & 472 & 2.1552 & 0.0229 & 0.2533 & 2.1087 & 42 & 1306 & 1.9539 & -0.075 & 0.1972 & 2.1383 \\
\hline 20 & 1572 & 2.3795 & 0.6021 & 0.2051 & 2.1112 & 43 & 1415 & 2.2666 & $\begin{array}{l}0.1145 \\
\end{array}$ & 0.1643 & 2.1727 \\
\hline 21 & 1291 & 1.989 & 0.1759 & 0.1945 & 2.1625 & 44 & 763 & 1.8158 & 0.7843 & 0.1546 & 2.146 \\
\hline$\overline{22}$ & 2044 & 2.0084 & 0.0099 & 0.2502 & 1.9467 & 45 & 1074 & 2.4975 & 0.2335 & 0.1584 & 2.0244 \\
\hline 23 & 3579 & 1.6015 & -0.006 & 0.2253 & 2.0626 & 46 & 1421 & 2.9425 & -0.044 & 0.1751 & 2.0302 \\
\hline \multicolumn{6}{|c|}{ To Continue } & 47 & 158 & 2.8137 & 1.6527 & 0.2051 & 1.7852 \\
\hline
\end{tabular}

Risk curves are exemplified in Figs. 3 and 4 as for only two prefectures: Hokkaido and Okinawa. The model fits very well with the risk curves of all the prefectures. Parameters of reduction factor $\left(\mu_{R}, \sigma_{R}\right)$ are compared with those obtained from the prefecture-by-prefecture distribution of the floor area at risk in Fig. 5. The mean of reduction factor was confirmed to have a good correlation with the mean of the floor area.
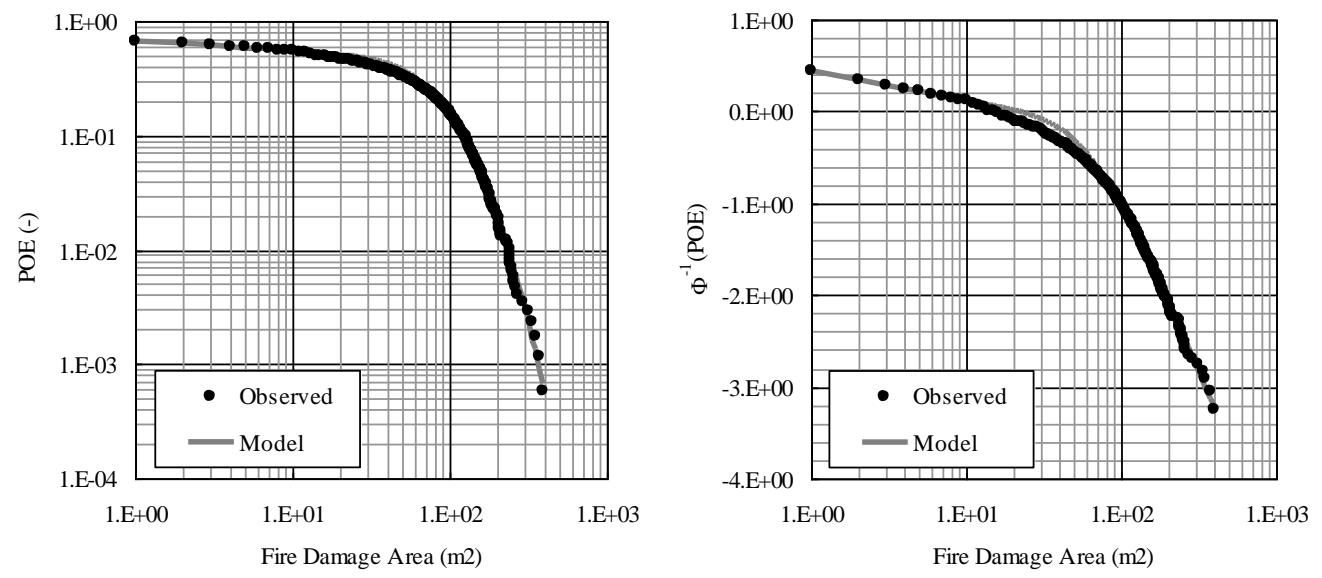

Fig. 3. Prefecture 1: Hokkaido. 

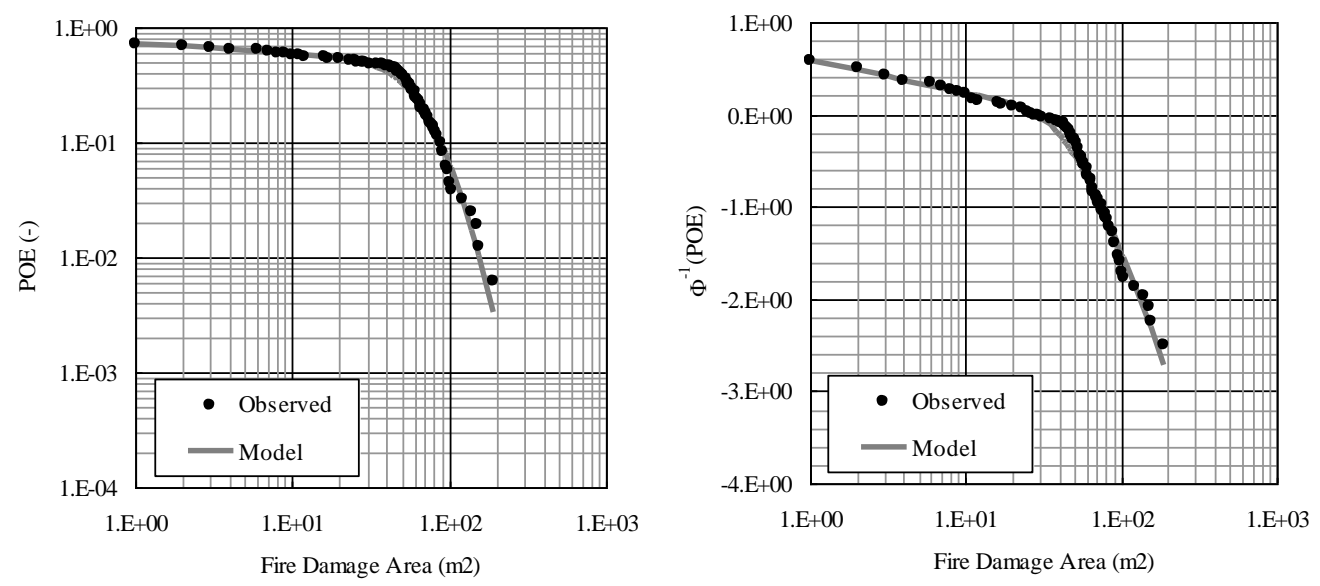

Fig. 4. Prefecture 47: Okinawa.
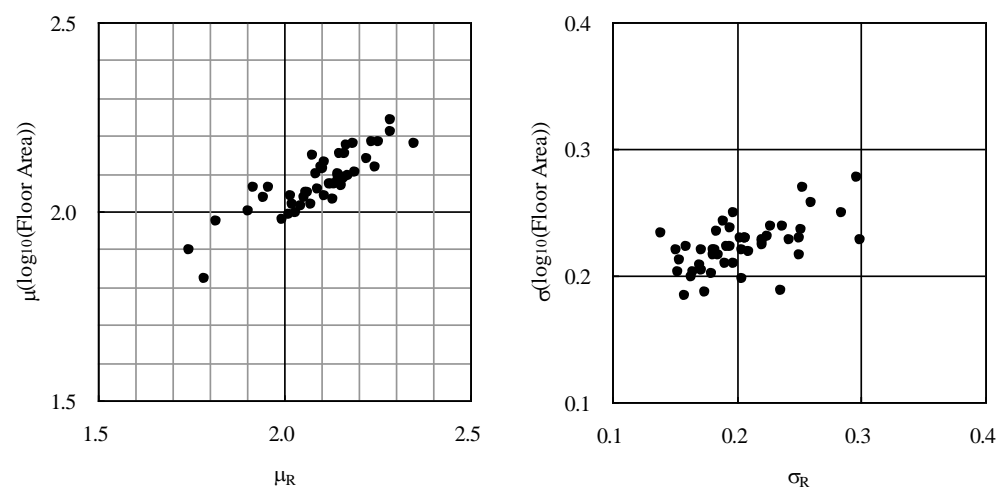

Fig. 5. Floor area estimations.

\section{FIRE SIZE AND TIME BETWEEN EVENTS}

Basic information on the three time intervals is given in Figs. 6-8: notification, response and intervention times. Regarding the frequency of notification and intervention times, numbers ending in fives and zeros seem to be preferred to fours and nines. The highest percentage of timber house fires had a notification time at $5 \mathrm{~min}$, a response time at $6 \mathrm{~min}$, and an intervention time in the 10 to $15 \mathrm{~min}$ range.
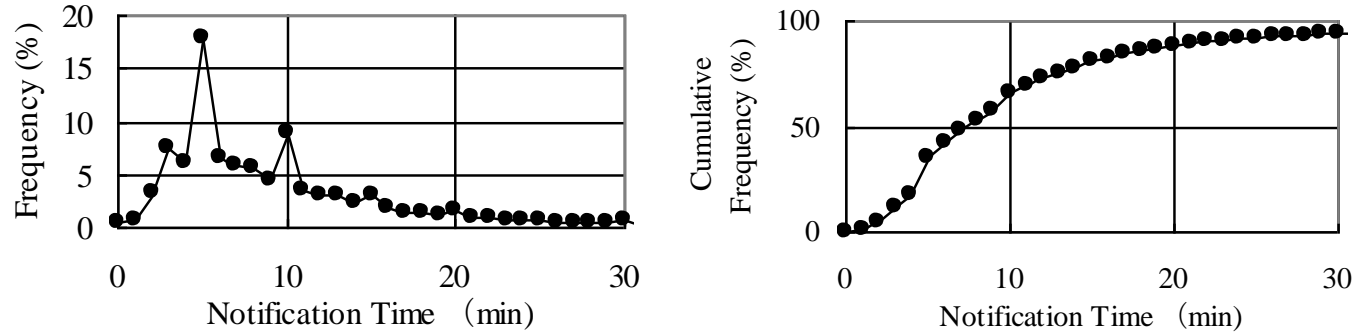

Fig. 6. Notification time. 

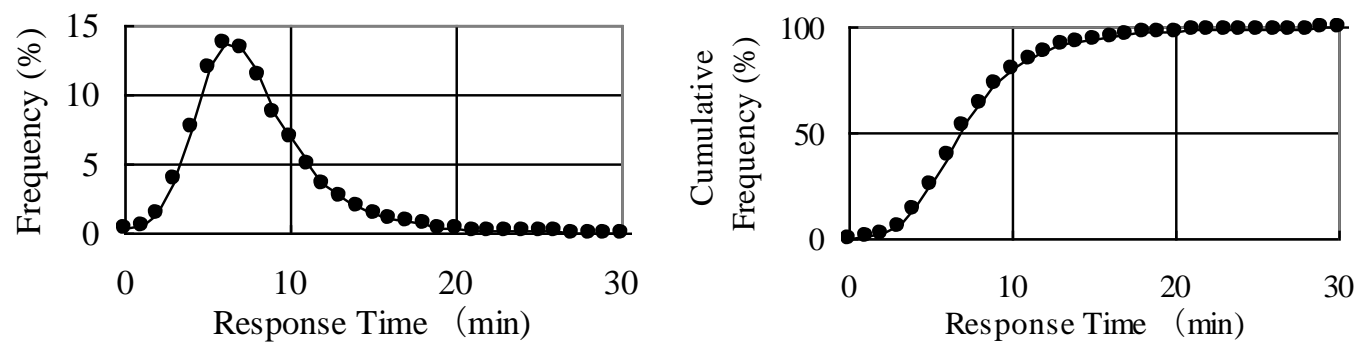

Fig. 7. Response time.
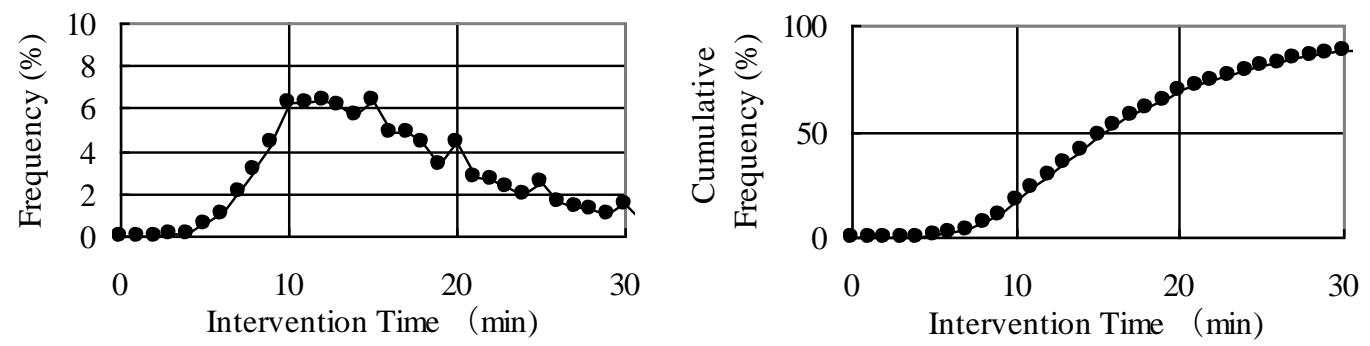

Fig. 8. Intervention time.

The exceedance probability is also depicted in Fig. 9 on double-log scales. The probability of the analyzed time intervals to exceed a certain level seems to be divided into two phases: primary and secondary. Up to some 30 to $40 \mathrm{~min}$, notification and intervention times seem to follow a single log-normal distribution, respectively, while the largest $5 \%$ or so of the time data appear to be governed by another distribution, where the negative slope of the exceedance probability becomes smaller, compared with that of the primary phase. Thus, the model given in Eq. 4 was used to obtain model parameters as in Table 3. As shown with solid lines in Fig. 9, the data fit well with the model based on the summation of two independent lognormal distributions, each representing primary and secondary phases.

Table 3. Time interval parameters.

\begin{tabular}{|c|c|c|c|c|c|}
\hline Interval & $\mu \mathrm{p}$ & $\sigma \mathrm{p}$ & $\mu \mathrm{s}$ & $\sigma \mathrm{s}$ & $\alpha$ \\
\hline Notification Time & 0.9074 & 0.2984 & 1.2961 & 0.6777 & 0.0871 \\
\hline Response Time & 0.8901 & 0.1766 & 0.7636 & 0.5476 & 0.0444 \\
\hline Intervention Time & 1.2186 & 0.2194 & 0.8669 & 0.8168 & 0.1773 \\
\hline
\end{tabular}
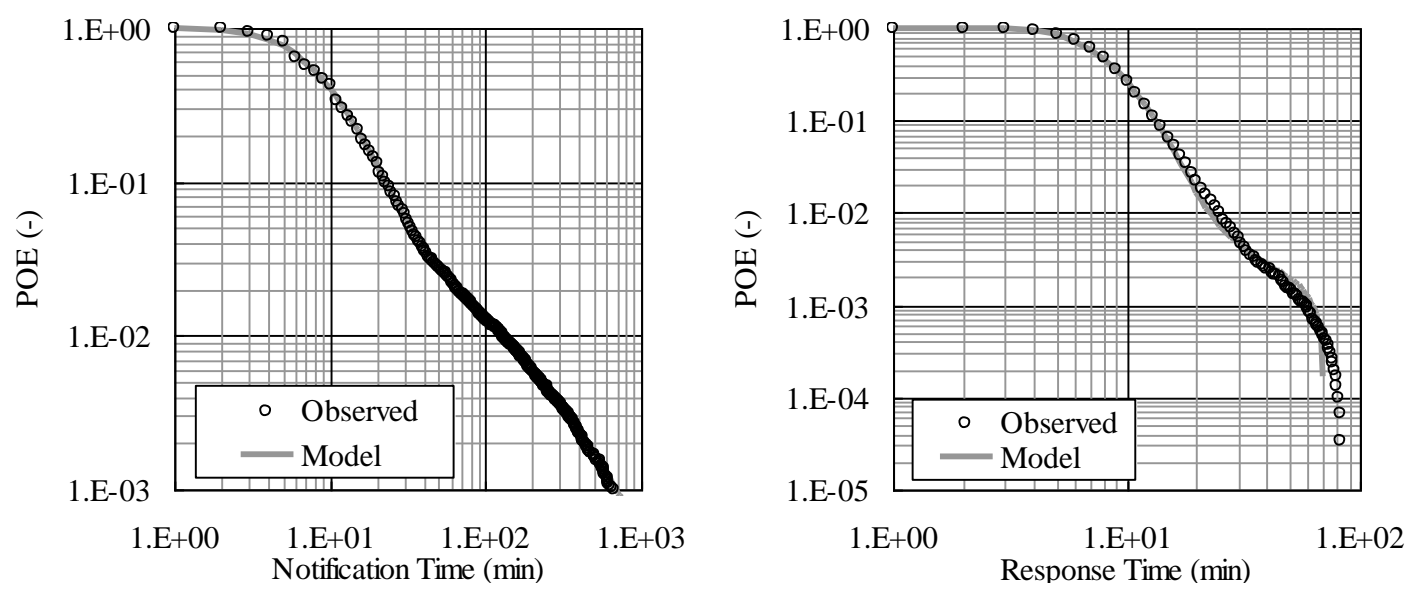


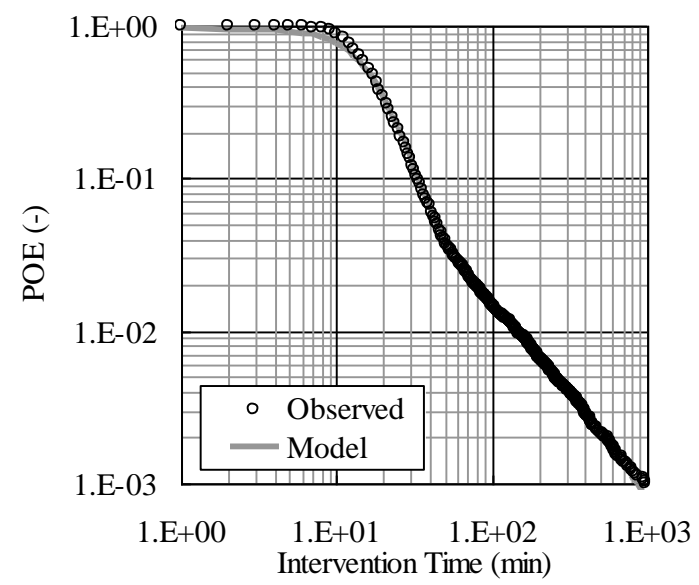

Fig. 9. Probability of exceedance of various time intervals.

Figure 10 is the summary of the relations between the time factors and the fire damage. Each plot represents the mean of base function obtained from the fire damage area based risk curve at each time interval. It is evident that the earlier a fire is responded to by the fire department, the smaller the fire size is, up to approximately $10 \mathrm{~min}$ of notification time or up to $20 \mathrm{~min}$ of intervention time. Response time, defined here as the difference of intervention and notification times, shows a smaller correlation with the fire damage.
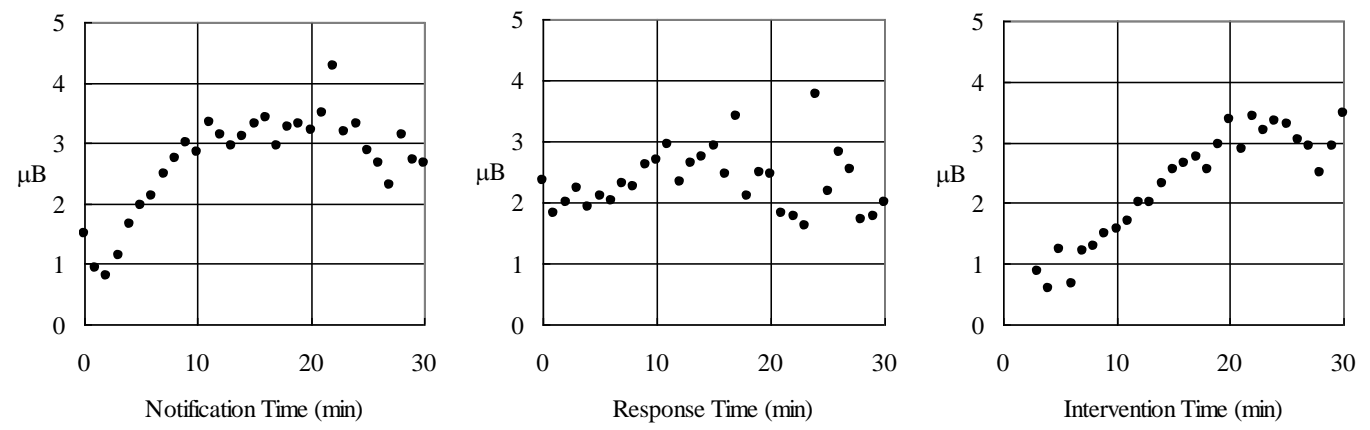

Fig. 10. Fire size parameter $\mu_{B}$ against time interval.

\section{FIRE SIZE AND DISTANCE TO FIRE DEPARTMENT}

The effect of distance to the closest fire station on the fire area is studied here. The statistics include distance to the closest fire station in $100 \mathrm{~m}$. This is why the distance frequency distribution (Fig. 11) has peaks at values ending in 0.5 and 0.0 . Fire records were categorized into separate groups according to distance up to $10 \mathrm{~km}$. Time and damage related model parameters were obtained from each distance group.
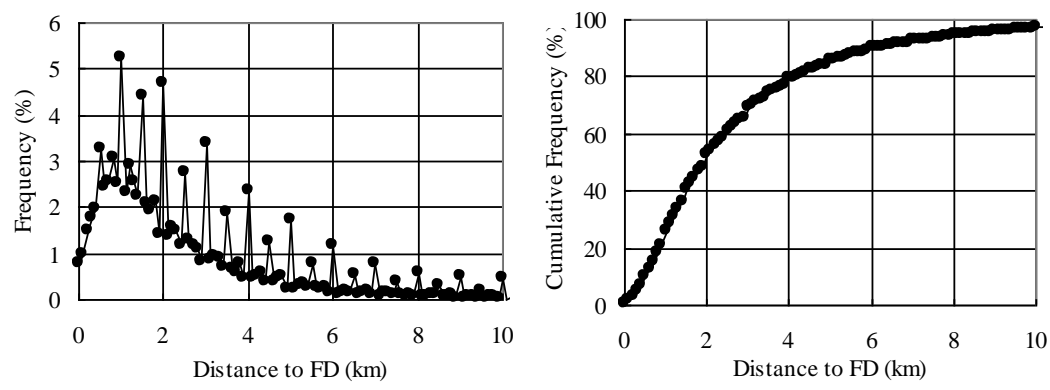

Fig. 11. Distance to the closest fire station. 
The relations between distance and time intervals are shown in Fig. 12. Both intervention and response times, not surprisingly, have positive correlation with the distance to the fire station.
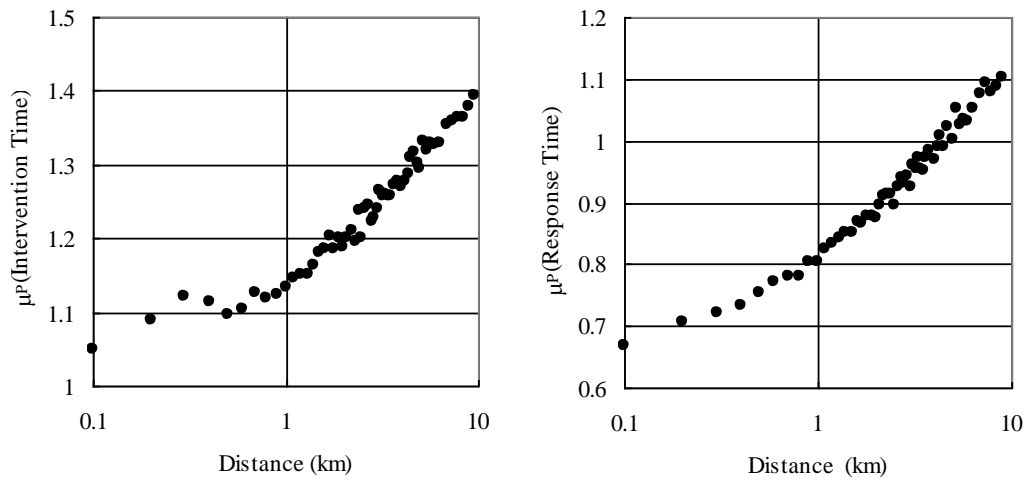

Fig. 12. Time parameters against distance.

Figure 13 is the comparison between distance and fire damage parameters: provability of a fire to exceed 1 square meter $(\operatorname{POE}(1))$ and the mean of basic function, $\mu_{B}$. As distance increases, these damage measures tend to be larger.
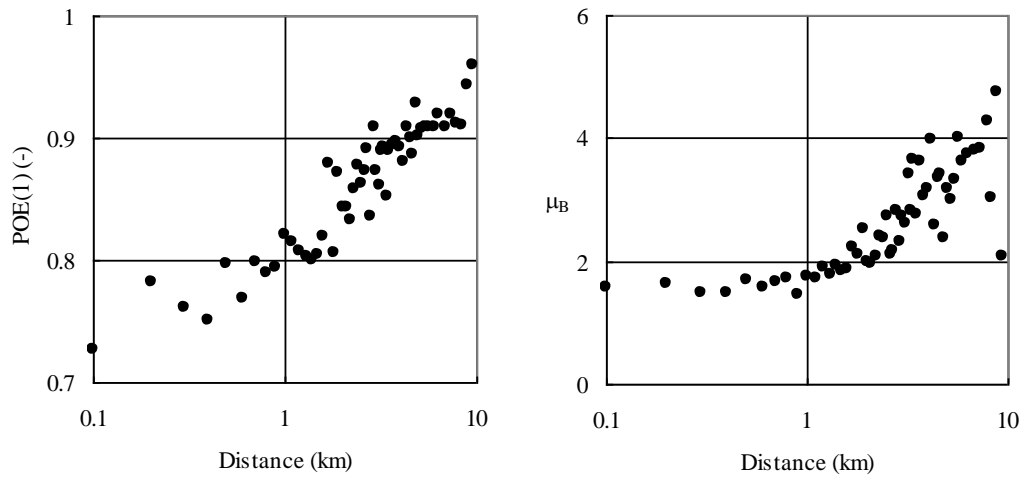

Fig. 13. Damage parameters against distance.

It should be noted that a strong correlation is found also between distance and $\mu_{R}$, the mean of reduction factor (Fig. 14). The positive correlation may be attributed to population densities. Usually as population densities increase, fire stations are situated so that they cover less and less geographic area, which may contribute to reduce response times. At the same time, as population densities increase, the price of land gets higher and the floor area at risk per home becomes smaller.

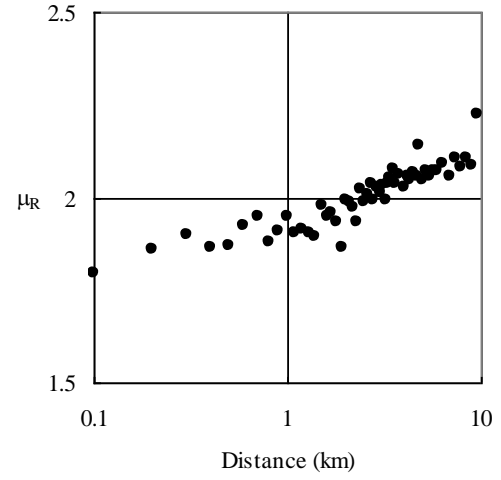

Fig. 14. Mean of reduction factor against distance. 


\section{FIRST-AID FIREFIGHTING BY OCCUPANTS}

As stated above, the statistics include information on the measures and successfulness of the actions taken by the occupants or automatic systems prior to the arrival of the fire department.

Although time information lacks completely in this regard, the nature of the measures taken might be helpful in speculating on the severity of the fire at the time of fighting, since bigger fires will be fought with more powerful measures, vice versa. Thus, the fire will be grown in the following order:

- What's at hand

- Fire bucket or other 'simple equipment'

- Fire extinguisher

- Automatic suppression system

- Hydrant and pump

The categories below will be compared with those above:

- $\quad$ Other measures

- None

Figure 15 compares measure by measure the ratio of non-zero damage fires to all fires. It is evident that fire without response by the fire department ("No Response") always show the lowest probability of the fire area to exceed the unity, while any fire, once responded to by the fire department, more than $70 \%$ tends to cause a fire area of more than 1 .

All in all, fires fought with "What's at hand" show the smallest probability to cause a fire area of more than 1 square meter, while "Hydrant and pump" shows the worst probability to give non-zero damage. Other measures lie somewhere in between these two extremes.

Similar tendencies can be seen in Fig. 16. Actions with "What's at hand" suggest that they take place the earliest as to notification / intervention time, "Hydrant and pump" takes the most of time.

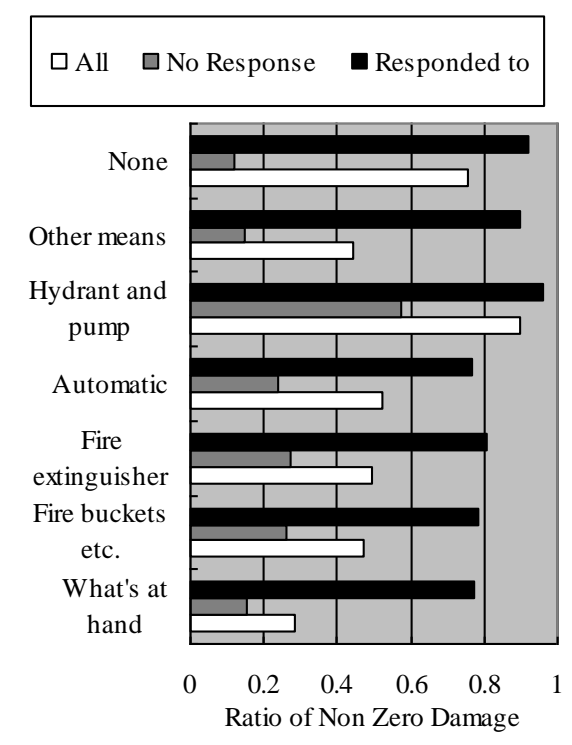

Fig. 15. Comparison of non-zero damage probability by measures taken. 


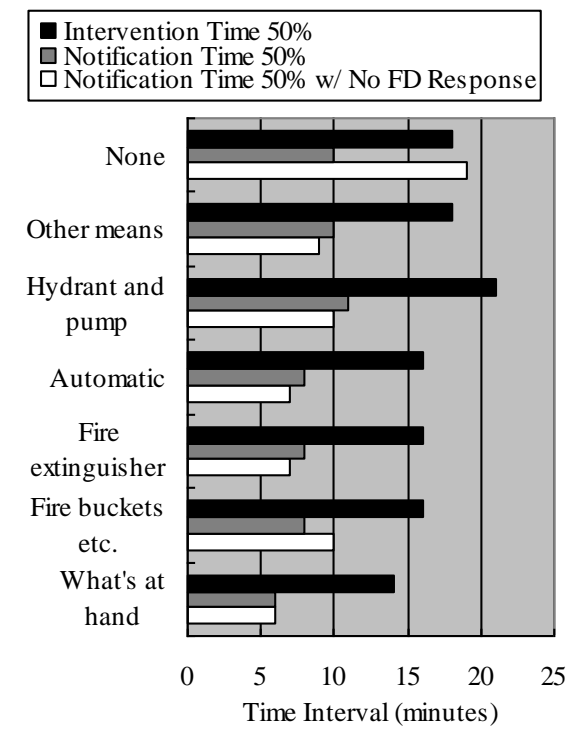

Fig. 16. Comparison of time intervals by measures taken.

\section{CONCLUSIONS}

Findings of the study can be summarized as below:

- It was confirmed that a proposed model based on the product of two complementary cumulative frequency distribution (CCDF) of log-normal distributions (base function and reduction factor) performs well in describing the overall profiles of fire risk in terms of area damaged by fire from minimum to maximum of a variety of buildings.

- Base function represents the of a fire to follow up until the fire area reaches the floor area at risk, while the reduction factor represents the effect of the limitation of the size of area at risk.

- Three time intervals on firefighting operation were studied: notification, response, and intervention times. Notification time is defined as the time between fire ignition and notification to fire department. Response time here includes dispatch, turnout, and travel times, as well as set up time. Intervention time means, for the purpose of the study, the summation of notification and response times. The probability of exceedance of notification and intervention times thus defined can be modeled by summing up two lognormal distributions, each representing primary and secondary time phases.

- The relations between the time factors and the fire damage were studied. It is evident that the earlier a fire is responded to by the fire department, the smaller the fire size is, up to approximately $10 \mathrm{~min}$ of notification time or up to 20 min of intervention time. Response time, defined here as the difference of intervention and notification times, shows a smaller correlation with the fire damage.

- Distance to the closest fire department shows also correlations with the final fire area. Not surprisingly, as a fire site get closer to the fire station, the damage tends to smaller. The size of floor area at risk also correlates with the distance to the fire station, suggesting the regional difference in floor size distributions of timber homes.

\section{REFERENCES}

[1] Ramachandran, G., (1982) Properties of Extreme Order Statistics and their Application to Fire Protection and Insurance Problems, Fire Safety Journal, 5: 59-76, http://dx.doi.org/10.1016/0379$\underline{7112(82) 90007-8}$

[2] Hasofer, A.M. and Thomas, I.R., 2003. Probability Distribution of Fire Losses, Fire Safety Science 7: 1063-1072. http://dx.doi.org/10.3801/IAFSS.FSS.7-1063

[3] Hanayasu, S., Kajiyama, M., and Sekine, K., (2002) Statistical Analysis of Industrial Accidents by Risk Curve, Research Reports of the National Institute of Industrial Safety, NIIS-RR-2001: 43-54. 
[4] Kobayashi, Y. and Nozaki, H., 2005. A Statistical Method to Evaluate Fire Risks in NonResidential Buildings in Japan, Fire Safety Science 8: 341-352. http://dx.doi.org/10.3801/IAFSS.FSS.8-341

[5] Hardin, B.O. and Drnevich, V.P., (1972) Shear Modulus and Damping in Soils: Design Equations and Curves, Journal of the Soil Mechanics and Foundations Division, ASCE, 98: GT7: 667-692.

[6] Handbook for Manual of Fire Reports ( $\left.8^{\text {th }} e d.\right)$, $4^{\text {th }}$ printing, Tokyo Horei Publishing Co., Ltd., Tokyo, 2003

[7] Kobayashi, Y., 2008. Factors Determining Probability of Exceedance of Area Damaged by Fire Fire Safety Science 9: 1003-1014. http://dx.doi.org/10.3801/IAFSS.FSS.9-1003

[8] Särdqvist, S. and Holmstedt, G., (2000) Correlation Between Firefighting Operation and Fire Area: Analysis of Statistics, Fire Technology, 36: 109-130, http://dx.doi.org/10.1023/A:1015450308130

[9] Benichou, N., Kashef, A, and Hadjisophocleous, G., Fire Department Response Model (FDRM) and Fire Department Effectiveness Model (FDEM): Theory Report, Internal Report No.842, Institute for Research in Construction, National Research Council Canada, 2002.

[10] Holborn, P.G. Nolan, P.F., and Golt, J., (2004) An analysis of fire sizes, fire growth rates and times between events using data from fire investigations, Fire Safety Journal, 39: 481-524, http://dx.doi.org/10.1016/j.firesaf.2004.05.002

[11] "Structure Fire Response Times," Topical Fire Research Series, Vol.5, Issue 7, U.S. Fire Administration / National Fire Data Center, 2006. 